Editorial

\title{
¿Educación para el mercado o para el desarrollo humano?
}

\author{
Education for the market or for human development?
}

La educación es un fenómeno humano sometido a un devenir histórico que está atravesado por variables sociopolíticas, socioeconómicas y socioculturales que se convierten en fuerzas modeladoras de dicho fenómeno en un momento socio-histórico dado. El momento actual está marcado por la globalización como fenómeno cultural y económico, el auge de las tecnologías de la comunicación y la información, por una economía de modelo neoliberal y libre mercado así como por una infinidad de problemas sociales mundiales y locales no resueltos. Estos son tiempos cambiantes y de crisis marcados por la complejidad y la incertidumbre como lo asegura Morin. Ante esto ¿Cómo debe plantearse la educación?

No es secreto que el mundo actual se mueve por los hilos de la economía, el capital y el mercado y que su tremenda incidencia moldea la sociedad y todas las actividades humanas, entre ellas la educación. Tal como lo sostiene Sánchez Paredes "La rápida y amplia expansión del gran capital ha permitido generar, por un lado, que las grandes potencias consoliden un poder no sólo económico y político, sino también ideológico". Pero, este sistema económico "reclama cambios en la educación, para que esta responda a las exigencias actuales de la economía". Esa gran expansión del capitalismo neoliberal junto con el estado de dependencia política y económica de los países latinoamericanos, y especialmente El Salvador, ha traído como consecuencia que dicha ideología neoliberal se haya insertado tan fuertemente en nuestra idiosincrasia que resulta completamente válido y natural pedir a la escuela que eduque para el trabajo, la empresa y el mercado.

La educación para el mercado o educación de mercado, que no es un concepto ni tendencia nueva, ha sido llamada así porque es una "educación" 
cuya prioridad es responder a las lógicas e intereses del mercado. La "educación" para el mercado opera en función de la producción, el capital, la rentabilidad y el crecimiento económico; define además a las personas que forman parte del sistema económico como "capital humano" y divide, de paso, al mundo en empresarios, empleados y consumidores.

En la lógica del mercado, la educación misma se constituye en un servicio sometido a las leyes de oferta y demanda. En ese contexto, tal como lo ilustra Marín, "las instituciones educativas más que centros de pensamiento, son vistas como empresas, en donde se debe garantizar la generación de ganancias económicas para unos pocos". Es una educación a la que acceden solo aquellos "clientes" que pueden pagar dicho servicio.

La educación para el mercado da prioridad a los programas o iniciativas que permitan el avance de la tecnología o el mejoramiento de la mano de obra pero solo en función de las necesidades y demandas del sistema productivo, dando preponderancia al crecimiento económico por encima del desarrollo humano. De igual forma, sus enfoques y procesos educativos enfatizan la cualificación de la fuerza laboral y la profesionalización entendida como el desarrollo de las actitudes y competencias laborales bajo el paradigma de la competitividad.

Pero además, la "educación" para el mercado supone la formación no solo de un sujeto para el trabajo, como parte de la fuerza laboral, sino también la conformación de un sujeto que consuma, ya que sin consumo no hay mercado, y sin mercado no hay capital, y sin capital no hay crecimiento económico. Se trata de configurar "un sujeto para el cual lo único que cuenta en la vida es el dinero, su consumo y su disfrute de los bienes materiales. De esta manera deshumanizado, el sujeto en cuestión pierde todo sentido de humanidad." Entonces, en su versión más cruel, a este sujeto de consumo "no le importa nada más que su consumo, puesto que eso es lo que al sistema le interesa, a ello le ha empujado, de eso vive; al sistema le interesa que, desde que amanece hasta que anochece, sólo debamos de vivir para el mercado." Este sujeto de consumo debe comprar incluso aquello que no necesita o que está fuera de su alcance. Este es el sujeto que se endeuda y compromete a futuro el valor económico de su fuerza de trabajo... sometido, y aprisionado así, por siempre, a un sistema omnipresente y perverso del que nunca podrá escapar.

Martha Nussbaum reconoce en todo esto una terrible crisis: la crisis de la educación. Esta es una crisis silenciosa de proporciones gigantescas y de enorme gravedad a nivel mundial que con el tiempo, si es que no lo es ya, puede llegar a ser muy perjudicial. El hecho es que las naciones del mundo, al buscar con tanto afán el crecimiento económico y al transpolar de forma acrítica y mecánica la economía de mercado a los procesos de formación, no se tomaron el tiempo para someter esta educación a un análisis profundo, no se hicieron en su momento ni se están haciendo ahora las preguntas correctas sobre el rumbo de la educación y, por ende, sobre el rumbo de la sociedad. Nussbaum advierte las consecuencias de esta crisis: 
Si esta tendencia se prolonga, las naciones de todo el mundo en breve producirán generaciones enteras de máquinas utilitarias, en lugar de ciudadanos cabales con la capacidad de pensar por sí mismos, poseer una mirada crítica sobre las tradiciones y comprender la importancia de los logros y los sufrimientos ajenos.

Al momento de desmontar y desenmascarar la perversión de dicho modelo, señala lo que este modelo deja por fuera:

Según ese modelo [...] la meta de toda nación debería ser el crecimiento económico. No importan la distribución de la riqueza ni la igualdad social. No importan las condiciones necesarias para la estabilidad democrática. No importa la calidad de las relaciones de género y de raza. No importan los otros aspectos de la calidad de vida que no están vinculados con el crecimiento económico.

Ya que producir crecimiento económico no equivale a producir democracia, ni a generar una población sana, comprometida y formada que disponga de oportunidades para una buena calidad de vida en todas las clases sociales.

Y es que la educación para el mercado ha forzado transformaciones profundas -mutaciones- casi siempre perniciosas a los Estados, sus sistemas educativos, y especialmente a la universidad, en el sentido que sus ofertas de formación, programas educativos, currículo, enfoques y métodos pedagógicos encarnen sus necesidades e intereses. Lo pernicioso de esta mutación es que elimina las aptitudes y capacidades esenciales para el desarrollo de una vida digna, completa y plena. Descarta las capacidades para desarrollar el pensamiento crítico, las capacidades vitales para la democracia, las capacidades netamente humanas que le ayudan a comprender mejor el mundo complejo en que vive y a solucionar la infinidad de retos y problemas que la misma vida le plantea.

La educación para el mercado ha eliminado de sus programas de formación, de su currículo y de sus cursos todo lo relacionado con las artes y las humanidades; al hacerlo ha descartado de tajo el desarrollo de las capacidades vinculadas precisamente al cultivo de dichas artes así como las capacidades de reflexión y pensamiento crítico que son capacidades imprescindibles para potenciar la cultura, la ciudadanía activa y la democracia. De hecho, esta "educación" ha descartado intencionalmente la facultad de pensar. Es más, de acuerdo con Nussbaum:

los especialistas en educación para el crecimiento económico no se limitan a hacer caso omiso de las disciplinas artísticas y humanísticas. En realidad, les tienen miedo, pues el cultivo y el desarrollo de la comprensión resultan especialmente peligrosos frente a la moral obtusa, que a su vez es necesaria para poner en práctica los planes de crecimiento económico que ignoran la desigualdad. 
Por otra parte, la educación para el desarrollo humano es esa educación que que educa en ciudadanía y democracia, que reconoce la dignidad y condición humana de cada persona y que devuelve al hombre el sentido de la vida. Pero además, es esa educación que busca generar

las oportunidades o "capacidades" que posee cada persona en ciertas esferas centrales que abarcan desde la vida, la salud y la integridad física hasta la libertad política, la participación política y la educación. Este modelo de desarrollo reconoce que todas las personas gozan de una dignidad humana inalienable y que ésta debe ser respetada por las leyes y las instituciones.

Entonces, ante la pregunta inicial ¿debemos insistir en una educación plantada como mecanismo perverso que enajena, manipula y deshumaniza al hombre, convirtiéndolo en una máquina utilitaria o retomar la educación cómo el medio inalienable que le regresa la dignidad, la humanidad, la facultad de pensar y el sentido de la vida al hombre?

Nelson Rubén Martínez Reyes

Editor

San Salvador, enero de 2017 